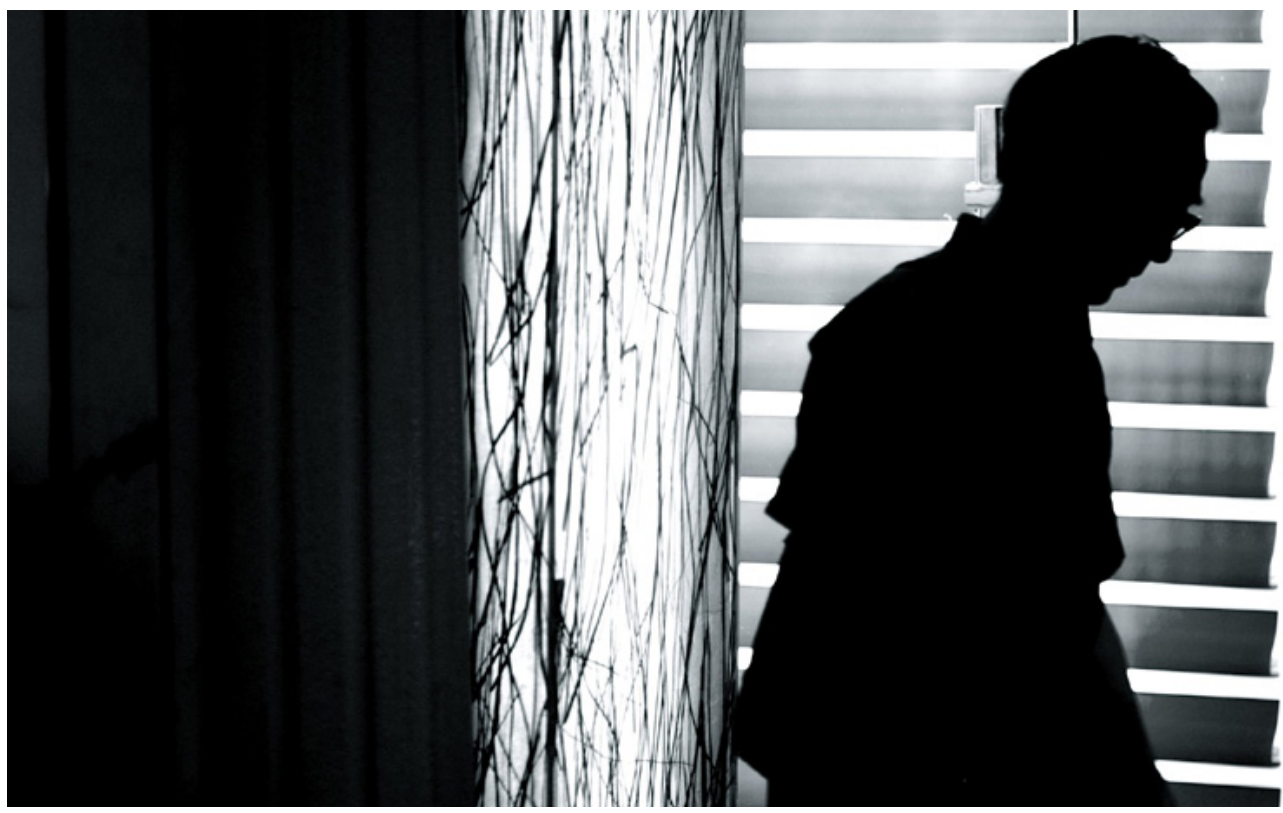

\title{
Hidden Rules and
}

PC: @aeshan05, Flickr.com

\section{the 'Heartache'}

of Chinese

\section{Government Officials}

Jie YANG

The rate of suicides among Chinese officials has been growing in recent years. According to media reports, these officials decide to end their lives because they suffer from psychomedical conditions, including excessive pressure, anxiety, and depression. Still, medical causes might not be enough to explain such a disturbing phenomenon. In this essay, Jie Yang argues that Chinese bureaucratic culture, particularly the workings of 'hidden rules', as well as complex power struggles and gender norms, play a fundamental role in causing these deaths. 
pressure (压力过大), anxiety (焦虑), or, most predominantly, depression (抑郁症) (Fang et al. 2011). For me, these accounts do not ring true. Starting in 2009, when I first encountered the phenomenon of 'officials' heartache' (官心病), I felt there was more at play than isolated and individual cases of mental illness. In this essay, I use ethnographic data from my research among mid-ranking officials in Zhangqiu, Shandong province, to consider the social and political contexts in which officials experience distress. Specifically, I argue that Chinese bureaucratic culture, particularly the workings of 'hidden rules' (潜规则), as well as complex power struggles and gender norms, contribute to this distress. Within this culture, women officials are confined to acting as confidantes or temptresses to men who, while ostensibly more mobile, nevertheless feel trapped in hierarchical binds, often with no way out.

\section{Hidden Rules}

A 2009 survey conducted by People's Forum (人民论坛), an offshoot of China's state-sanctioned People's Daily (人民日报) newspaper, showed that out of 5,800 officials surveyed, 64.65 percent believed that pressure felt by officials was mainly due to the impact of 'hidden rules' on one's political prospects (Liu 2014). Yet, to date, there has been no systematic study of these rules. What they are and how they operate remains mysterious. One midranking official in charge of the road system in Zhangqiu tried to capture the hidden rules by describing the task of conforming to the shifting demands of higher-ups at work:

The most difficult task is to understand what superiors think ... . [They're] evil and fickle. They don't say directly [what they want] to enhance the secrecy of their power. You have to interpret them accurately and speak accordingly. Everyday you walk on thin ice; if you are not careful you will fall into deep waters, wasting all your efforts at pretentiously humbling yourself. No matter how healthy you are, you will sooner or later become depressed as it's so important to twist yourself to fit the system.

This sense of precarity leading to distress dominates accounts of hidden rules among my informants for good reason-this instability has historical roots. The term 'hidden rules' was coined by Chinese journalist-turnedhistorian $\mathrm{Wu} \mathrm{Si}$ in the late 1990s. In a book published in 2001, Wu examines behindthe-scenes practices of ancient Chinese officialdom to illustrate how established rules were undermined by hidden alternatives, suggesting that backdoor wrangling has always characterised the Chinese bureaucracy.

The difference today, according to one of my informants, may lie in the proliferation of ways to get ahead informally. From soliciting extra funds, to cultivating favouritism or factionalism, intensified striving within officialdom creates pain and frustration for many. Hidden rules shadow formal procedures, attaching to, complementing, bypassing, or twisting the operation of formal, established rules in Chinese institutions. They can be a deeper set of unjust principles underlying the way that crime, punishment, and power are handled. To fall victim to them is to be, in Chinese, 'hidden ruled' (被潜规则).

These rules constitute informal codes of behaviour that range from prescriptions for proper demeanour, to minor rule-bending, to more serious transgressions aimed at amassing wealth or benefits, including the cultivation of nepotism and factionalism, flattery, and bribery. These are interest-based strategies defining access to resources, including career advancement and pay raises. Hidden rules underpin what amounts to an autocracy-the idiosyncratic rule of individuals rather than the predictable rule of law. By their very nature, hidden rules are elusive, highly contextual, and unpredictable; their fluidity and the uncertainty surrounding them can consume people cognitively and affectively, turning 
officials into, in their own words, 'patients of power' and triggering anxiety, distress, and even suicide (He 2011).

Most of my informants have told me that navigating the hidden rules of the bureaucracy requires 'embodied understanding' (体会). This means they must be able to read body language and what it implies. At work, a look, a wink, or a pat on one's shoulder can signal particular intentions, depending on context. Important information may be expressed in a pause in conversation, requiring subordinates to fill in the silence with the correct meaning. Failure to understand this physical aspect of hidden rules leads to unexpected consequences.

And yet, for all the effort it involves and the high cost to officials' mental health, following hidden rules does not always equal success. Indeed, hidden rules are an idiom invoked by many to interpret widespread injustice-for example, based on increasingly commercialised human relations-and as a means of filling in the gap resulting from part of the system being unobservable and unfathomable. In my interviews, officials often deployed the term 'depressed' (抑郁) and other psychomedical terminology to describe the psychological effects of the practice of hidden rules.

There is another important facet of hidden rules that increases the distress of officials: they operate based on essentialised gender norms. According to my female informants, they are effectively excluded from many aspects of this opaque system, unable to use hidden rules to their own benefit. Instead, these rules leave only minor roles for them in relation to male colleagues. A deputy director in her early forties at the local education bureau once stated:

They [male colleagues] are well connected with one another as they have time to socialise after work at dinners and drinks. Those occasions are informal but very important to exchange opinions and form cliques. But we are seldom considered as suitable for such [masculine] occasions; we are also busy with children and family.
They invited me to such meetings when they needed me to help them achieve certain purposes at work; otherwise I'm not invited.

Within the bureaucracy, women reflect, deny, or enhance male power, but cannot, except in rare cases, accumulate or enhance their own. In rare cases when women do have power, they are often perceived to have 'slept up' or have powerful family background.

Hidden rules thus cause widespread strife in the bureaucracy: from top to bottom within its hierarchies, between men and women, and from peer to peer. These rules therefore counter a longstanding emphasis on the part of the Chinese state to achieve 'social harmony' (社会 和谐). In this way, we can think of hidden rules through the lens of deviance. Lu Xiaobo (2010, 22) defines official deviance as behaviours that deviate from the prescribed norms of a regime, in which individuals or groups exploit the formal organisation instead of working for it, and in which personal roles take precedence over organisational roles.' Lu suggests that such deviance is derived from involutionary change within a postrevolutionary regime, a process whereby a revolutionary party, while adopting 'modern' (i.e., rational, impersonal, harmonious) structures, fails to adapt to the routinisation that characterises such modern bureaucracy, and is thus unable to maintain its original revolutionary identity. In the case of China, then, there is a conflict between modernisation and a bureaucratic culture that has remained largely unchanged since before the reform era.

Yet, recall that according to most media accounts, officials' suicides are blamed on psychological problems. Why this failure to see the bigger picture of bureaucratic culture? To answer this question, it is useful to compare Chinese hidden rules to other painful bureaucratic practices that exist elsewhere, such as 'mobbing' in the Italian context (Molé 2012). Molé describes 'mobbing' as psychological and emotional workplace harassment. While mobbing is linked with 


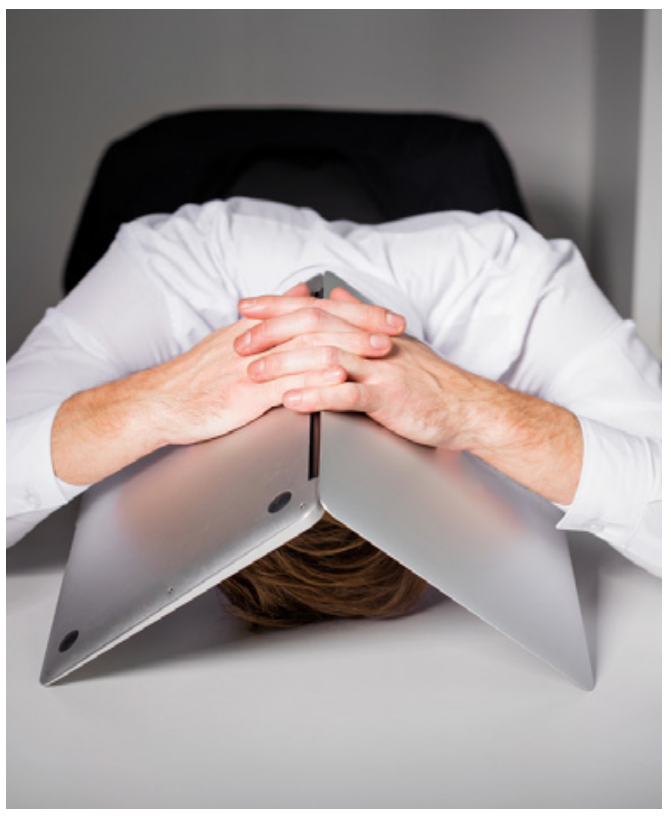

PC: @socialmediasl444, Flickr.com

neoliberal policies and organisational coercive pathology, through Molés ethnographic study, we see that these broad economic, social, and historical structures are made visible in the day-to-day injustices, frustrations, and suffering of workers. Like hidden rules in China, mobbing is imagined, experienced, and treated as a health problem and a form of psychological violence with dire consequences. While we know that hidden rules have shaped Chinese officialdom for thousands of years, reports of officials' suicides mostly ignore this context. That these hidden rules have become increasingly entangled with neoliberal market practices, intensifying the precariousness and ethical conflicts Chinese officials experience, also goes unsaid. Like in the case of mobbing, the focus of the analysis remains narrowly limited to individual mental health problems, rather than the intractable issue of reforming China's gigantic bureaucracy.

\section{Binding Effects}

Hidden rules have a number of consequences that my informants described in detail. I have noted that these consequences can be thought of as irresolvable conflicting positions-what Gregory Bateson (1972) called 'double binds'. Bateson used the term to refer to social relationships that are subject to chronic invalidation through paradoxical practices, and that require permanent management of contradictions. No matter what a person does, he/she cannot win. Existing scholarship shows that double binds are pathogenic (Bateson et al. 1956). A person caught in constant double binds may develop schizophrenic symptoms. Doublebind conditions produce anger and negatively affect people's ability to find meaning in life (Watzlawick et al. 1967). I believe this is what happens among Chinese officials, culminating in widespread 'existential crises' (生存危机) among them.

For example, many of my informants stated outright that they must behave like a 'twofaced person' (双面人) in order to survive their work life. That is, due to the demands of the hidden rules, they are caught between contradictory roles: claiming to serve 'the people' through their work while attending to their own personal interests. Being two-faced helps them balance sacrifices (anxiety, distress, humiliation) and gains. In this sense, they are masters of themselves in the guise of public servants. However, their contradictory roles engender distress. One informant in Zhangqiu described the psychological toll of this double bind: 'You have to be cautious and calculating whenever you're at work to avoid pits and traps. At some point, you feel so exhausted and so frustrated that you want to end it all.'

Another double bind created by the hidden rules involves the contradiction between doing a good job and serving superiors. In the absence of strong checks and balances in China's system of one-party rule, the cost of breaching established laws and following one's own rules is generally low. This lack of 
accountability can transform 'public power'delegated through formal mechanisms of institutions to serve state interests-into 'private power' for achieving individual agendas. Once an official is an 'insider', he spares no effort to maximise economic and social benefits for himself. I say 'he' because rarely is a woman able to accrue such private power. Thus, activities in the bureaucracy flow from the personal preferences of insider men. Leaders tend to prefer subservient rather than competent subordinates. Those who are reluctant to give up pride and character to curry favour with higher-ups are marginalised. Such 'reverse elimination' (逆淘汰) fosters injustice and causes distress and anger in China's bureaucracy. Even worse, those who do not submit to the power of higher-ups are often given 'smaller shoes' (小鞋) to wear, through which they are intentionally made uncomfortable or demoted.

Further, the system of appointing officials from top down rather than electing cadres from bottom up makes officials responsible to superiors more than to subordinates. Many officials take up a negative ethos of not causing trouble or giving superiors extra work. They thus dislike innovative ideas that would disrupt the status quo. They transfer the pressure at work to subordinates and keep pressure and conflicts at the bottom, pacifying their subordinates in various ways so that they will not go over them to report to their superiors.

My ethnography provides a good example of this double bind related to superiors, flowing from the workings of hidden rules, and leading to reverse elimination. At a local broadcasting bureau in Zhangqiu a few years ago, two competitive candidates were up for the job of departmental director. Neither of them got the job. Instead, a man surnamed Wei, who had connections with the company president, was appointed. Yet, ironically, the new position and associated pressure pushed the new director into a downward spiral. Wei was not good at his job and largely relied on one of his subordinates, a young, capable colleague surnamed Liu, to assist him. Because Liu was so young and new to the company, Wei was able to use many of his work and research findings to impress senior leaders. This strategy eventually backfired, however, when, during face-toface meetings with important clients, Liu's excellent performance outshined Wei, who became not only jealous of his younger protégé, but also suspected that Liu had betrayed him by directly interacting with and impressing the senior leadership. Trapped between this capable subordinate and senior leadership, Wei transferred Liu to another department.

Interestingly, Liu himself later expressed relief to me about his transfer. He too faced great pressure to help Wei hide his incompetence. At the same time, he was also being constantly monitored, as Wei was paranoid about his interactions with superiors and peers alike. Liu suspected that Wei was exhausted from his daily performance of (fake) competence, and the never-ending effort of exploiting subordinates while fooling his superiors. Yet, Wei maintained his position in order to hold onto the power and privilege he enjoyed as director. In fact, there is no real way for him to go back in this case without completely losing 'face' and destroying his career. Both Wei and Liu were in binding situations. The man promoted through hidden rules and his subordinates both suffered from the effects of reverse elimination, and consequential double binds and distress.

\section{Between Pathological and Therapeutic}

Far from emerging spontaneously from someone's unhealthy mind or uncontrollable impulses, distress and depression among Chinese officials result from deep cultural, historical, and institutional realities that reinforce hierarchy and gender norms. The hidden rules of the bureaucracy are contextual, vague, and ambivalent, yet powerful and instrumental in a bureaucracy with an 
incomplete, inefficient legal framework. As a result, these rules become passwords for accessing resources and an expression of unspoken social injustices.

Hidden rules create subjects who oscillate between formal and informal rulebooks, public and private arenas, words said and unsaid, and potential and manifest power. A desire for security and protection may lead officials to cultivate paternalistic relations with superiors and seek to become 'insiders' themselves, all the while anticipating precariousness, uncertainty, and flux. Hidden rules turn workplaces into an arena for volatile interdependency. People see others as extensions of themselves, using them or bypassing them to achieve their own goals. Such dynamics have become an important source of uncertainty and anxiety, contributing to the moral and ethical conflicts among midranking government officials, and thus to anger, distress, and even suicide.

In my research, I have discovered that, ironically, hidden rules are both pathological and therapeutic, depending on the person and the instance. While most of my informants resent these rules, as they suffer within them, such resentment is mitigated once they benefit from the system. It is thus less workplace hierarchies as such that trigger depression, than the shock of these rules turning against them. The positionality of mid-ranking officials-both sufferers and contributors of hidden rules-results in precarity, binds, and frequently personal defeat. Lagging bureaucratic reform in a period of officiallysanctioned 'harmony', as China seeks global preeminence by becoming fully integrating into the global economy, silently sets the stage for these experiences. Those who do not understand or use hidden rules do not benefit from relative freedom or mobility and have no control over their promotion or prospects. Officials I interviewed in general felt that they have no sense of control over their job and work environment in a workplace where the practice of hidden rules predominates.
These practices are subtle forms of oppression that may transcend class and kinship. China scholars have recently focussed on the class stratification intensified by economic restructuring, but a focus purely on class dimensions tends to obscure personal power and its other significant dimensions. In this essay, I draw attention to the culturallyspecific and subtle forms of personal submission, humiliation, degradation, coercive incorporation, and existential crises that are not tied to class-based hierarchies and that can contribute to people's distress and suffering in China. 